any magnitude, are much better issued in parts, their purchase being thus

it a more convenient; but both authors and publishers should make appear of honour, as they would find it one of profit, that these should work punctually at the periods promised. The paging of the present ork being continuous, the three parts may be bound in one volume.

$M$

Dical History of the Expedition to the Niger, during The Years 1841-2. Comprising an Account of the Fever WHICH LED TO ITS ABRUPT TERMINATION. By James Ormiston M'William, M.D. Surgeon of the Albert, \&c. 8vo. pp. 287. Churchill, 1843.

WHo has not heard of the ill-fated expedition to the Niger? It is curious impreaths and disasters, on a small scale, make a more vivid and distinct wholession on our minds, and excite more acutely our sympathies, than shipwrale slaughters and the destruction of whole fleets and armies. The remereck and sufferings of Byron and his little crew will be read and will bered, when the battle of Borrodino-perhaps even of Waterloo, tunes, forgotten! We can form a distinct idea of the personal misforthe destivations, and hardships of an individual, or of a boats' crew-but Whelms ustion of Napoleon's army, in the retreat from Moscow, overeye. fever, On the other hand, we can easily conceive a dozen men groaning in one solitary a tropical sun, and between the decks of a small vessel, while to the itary man is left for duty-and he steering the vessel and attending The engine without the assistance of a single hand!

very medical portion of the volume-the account of the fever-is a waticall one-and we dare not indulge in giving much of the mere adapted narrative, which, though interesting to the public at large, is not Eved for a medical journal.

lent pury one knows that the extinction of the slave-trade was the benevothe purpose for which this unfortunate expedition was projected, besides Africa greater object-the spread of Christianity among the natives of Were fit Three steam-vessels, the Albert, the Wilberforce, and Soudan, had fitted out with every possible attention to the health, the comfort, we Geolmost said, the luxury of the officers and crews. Divines, Medici, plied logists, Mineralogists, Botanists, Astronomers, \&c. were liberally supThe cre well as a profusion of medical stores and culinary preparations. 53 crews of the three vessels consisted of $178 \mathrm{men}$, of which there were seamen. inclusive of civilians and engineers -67 white, and 28 coloured anythin. We must pass over the voyage outwards, as it does not present the thing particularly interesting. The expedition entered the Mouth of died of on the 13th of August 1841, and two days afterwards, a German endemic fever, with delirium and tremors, but not supposed to be of an ndemic character. A considerable part of the narrative is occupied with 
the nautical difficulties attendant on the ascent of the river, and with descriptive sketches of the topography and population on both banks 0 that pestilential stream. These we must pass over. They had passed the great Delta of the Niger, and were preparing to explore the valley of that river, without any symptoms of illness, when, on the 4 th of September (1841), a fever of the most malignant nature broke out in the Albert, an almost simultaneously in the other vessels-not abating till the whole es pedition was entirely paralyzed! Between the 12th and 17th of September, the sickness still increasing, the model farm was established a Stirling Hill, and it was now evident that some decisive step must be taken. One vessel, therefore, the Soudan, was selected to descend to the open sea, and on to Fernando Po, with all the sick. She did so on the 19th September-but it was soon found necessary to despatch the Wilberforce in the same direction, leaving the Albert to prosecute the royage farther up the river.

The settlement of the now famous Moder F FRM, at the confluence of the Niger and Tchadda rivers, includes a tract of land 16 miles by 5 in extent. Stirling Hill is two hundred feet above the level of the river, and near it rises Mount PatTEH, to the height of 1160 feet.

Having located the settlers, the Albert, sadly reduced in the number of her officers and men, but full of hope, started on her ascent of the riveri with the view of reaching Rabba; but on the third day, (22nd Sept.) three officers, including the captain, were laid up with the fever-and three others, in the course of the evening, were added to the list. By the $3 \mathrm{rd}^{\mathrm{d}}$

October, there were only one white seaman, one sergeant and one private marine - Dr. Stanger, Mr. Willie, Mr. Huxley, and Dr. M'William himself, capable of doing duty!! The season was advancing, the rivel beginning to fall, and, under such circumstances, it would have been sheet madness to attempt a further prosecution of the expedition. On the 4 th of October, therefore, the Albert weighed, and began to drop down the fatal river. Dr. Stanger undertook to manage the engine, while of author was necessitated to work the ship, in addition to his profession duties. In steaming downwards, they touched at Stirling Hill, and fould the white part of the new settlers in a sad plight. They therefore $\mathrm{re}^{\mathrm{e}}$ embarked all but the blacks, and continued their course towards the long wished ocean. On the 16th October they fell in with the Soudan, at the entrance of the river, and both vessels proceeded to sea, bound for Fer nando Po.

From this time, the expedition may have been considered at an end, though many of the officers and men fell victims after their departure froll the pestiferous stream.

\section{Vital Statistics.}

Of the total number of whites in the squadron, viz. 145 , there were ${ }^{\text {no }}$ less than 130 cases of fever, and 40 deaths! There were 158 blacks, of which none died, though eleven had fever. This speaks for itself. 


\section{The Fever.}

There was little uniformity in the premonitory symptoms. A number of the patients had head-aches-scintillations along the spine-and chilliburningeceding the attack-others complained of debility, and some of treming sensation in the epigastrium. Then came giddiness, lassitude, looker, foul tongue, small quick pulse, and general oppression. The eyes "

"Character, course and duration of the symptoms.-The accession was seldom excitemented by very marked shivering, yet previous to the period of vascular sake of the the patient usually experienced a sensation of coldness, and for the would of warmth would fain have exposed himself to the rays of the sun. He of in shortly express a wish to lie down, and would complain somewhat suddenly dry parce of headach or giddiness, and intense heat of the skin, which had a dyspnes in feel, restlessness, intolerable nausea, and difficult breathing. The tressing in several instances, particularly in my own case, was extremely disvomitin, and continued from one to four hours, until relieved by spontaneous nent sym, or the occurrence of diaphoresis. Headach was with some the promicord bymptom during the hot stage, and the feeling was described as that of a tongue tightly girded round the temples. The thirst was very urgent: the indent was foul in the centre, moist, clean or reddish, and invariably marked by occasionalls on the edges. The countenance was more or less flushed, the eye feeble; . quantityirst urgent, bowels constipated, and urine passed often and in small

but ofte. There was in general tenderness of the epigastrium, sometimes acute, "In not discoverable unless upon pressure.

death some cases, coldness of the stomach was complained of some days before bours, A subsidence of febrile action in general followed in from three to six came, or at all events, the symptoms if continued beyond the latter period beof much mitigated. Diaphoresis came on, the thirst moderated, and the signs period ession in a great measure disappeared. The principal complaint at this cases thas from the disagreeable odour of the perspiration, particularly in those omell of subsequently proved fatal. I was not sensible of this peculiarity in the sereral of the perspiration in my own case, but I perceived it very distinctly in been others. The sweating continued until from eight to twelve hours had hau occupied by the whole paroxysm. The patient, although considerably exdicated, expressed himself as free from all trouble, and the countenance also inthe ac improvement. This seemingly favourable change did not last long, for the accession generally returned in from six to ten or twelve hours. Occasionally rous ipite extended to twenty-four hours. In a few cases, there was a treacheinvarinterval of forty-eight hours, in the early period of the disease; but these to have y'assumed afterwards a low malignant type. The fever in them seemed "The rested only to give strength for a fresh accession.

on, dise accessions did not seem to observe any law of periodicity. They came howereppeared, and returned at all hours of the day and night. The evening, after th, was a more common time of accession than any other; in which case, stages in cold sensation had passed off, the paroxysm generally ran through its the hour the course of the night, and had suffered a considerable remission by "I I of breakfast (eight) the next morning.

These a few instances the remissions were as complete as in the interval of ague. fever were, however, only exceptions to the general rule, for total absence of If was indeed of rare occurrence during the course of the disease." 134. If no material improvement took place by the 8 th or ninth day, the 
prognosis was gloomy - the fever then assuming a low asthenic form. Local pain was seldom complained of-and, in several cases, the patients never made any complaint at all!

In farourable terminations, the remissions became more distinct, and the intervals more marked and lengthened-the countenance assuming a mort natural expression - the skin more moist-the thirst diminished-and the pulse softer. At this period, diarrhœa was by no means uncommon-and also a copious diuresis, with a desire for food. Of the contingent symp toms the most prominent were delirium, yellowness of skin, and convul sions of various parts of the body. In no case was there "black vomit."

\section{PATHOLOGY.}

The following were the appearances in eight cases examined on board the Albert.

"Head.-In two cases where the head was examined, softening was found in the corpus callosum and walls of the ventricles. In one case there was a smal quantity of serous fluid in the base of the brain, and an unusual proportion in the ventricles. The dura mater was always sound. The pia mater in one cas red and injected. No subarachnoid effusion was observed.

"Thorax.-The contents of the thorax were in nearly all cases healthy in ap" pearance. Adhesions between the costal and pulmonary pleure were found in one instance, with tubercular deposits in the lungs in the state of induration. II another, a cartilaginous state of the tricuspid valves, with serous effusion in the left pleural sac.

"Abdomen.-The peritoneum and its processes, as well as the surface of the intestinal tube, had in general a bilious tinge.

"The Stomach.-In several cases the stomach contained from one to five ounces of yellowish-green fluid. The mucous coat was invariably softened, whether this fluid were present or not. In three cases livid patches were variously dise tributed over the inner surface of the stomach, becoming more distinct when the mucous tunic was scraped off, exhibiting stelliform nuclei in their centres. II two cases, the livid marks were arranged in the form of parallel streaks. These pathological appearances were chiefly in the splenic extremity of the stomach and near the pylorus. In one case there was remarkable venous arborescence 0 of the exterior of the stomach, attended with general engorgement of the ports system. Small points of ulceration were observed in three cases, and sligh thickening of the mucous lining in one instance only.

"Duodenum.-The lesions observed in the duodenum were of the same nature as those in the stomach, but much less marked. In one case the lower portiols of this gut contained a yellowish secretion, of the consistence of mucus.

"The Jejunum was free from disease, and likewise the ileum, until within three feet of its lower end, where were observed, softening of the mucous lining genes rally and livid spots. A series of small ulcerations were seen in four cases. In one, the membrane was thickened, rough, and the ulcerations had nearly perforated the bowel; this case proved fatal by terminating in dysentery. agminated glands of Peyer were distinct and enlarged in three cases.

"Colon.-The colon was usually nearly empty. On these occasions a dark, bilious, pultaceous matter was found in this portion of the tube, but in $\mathrm{sm}^{2}$ ll quantity only: it was viscid and tenacious, adhering to the mucous tunic: where lividity or ulcerated points were found at the lower end of the ileum, the same lesions were seen to exist on the arch of the colon. Softening of the mucous $\mathrm{coa}^{\mathrm{t}}$ was remarkable in three cases. In that of the case of dysentery already men- 
tioned, there was softening of the tunic where it was not ulcerated, and indura-

tion and elevation round the edges of the ulcerated patches.

"Liver. - The liver was congested in one instance; larger than usual in two

other. It was anemious in two cases where the patients died early, and on two

latter casesions when death took place long subsequent to febrile action. In the

being sliced this organ was of a pale gray colour, and had a dry appearance on

" sliced. This condition was not confined to one lobe.

consiste-bladder. - The gall-bladder was distended with bile of the colour and

seventh, an tar in three cases : one of which was fatal on the third, one on the

was nearly the other on the ninth day. In another instance the gall-bladder

weeks after flled with bloody bile. The man in this case died suddenly, many

"The the fever had left him.

Louis as enlarged condition of Peyer's glands, which is regarded by Chomel and

eight th constant in the typhoid fever of France, occurred in three cases out of

tion died were examined. In four cases, the subjects of which with one excep-

observed. early, slight ulcerations of the gastro-enteric mucous membrane were

that the . This fact is worthy of attention, inasmuch as it would seem to imply

tem, ind cause of the river fever, in whichever way it is introduced into the sys-

even induces an unhealthy action in mucous surfaces much more rapidly than

tions the low typhoid fevers of France. Chomel does not consider that ulcera-

also, softeniace in typhoid fevers earlier than the twentieth day, when there is,

it whictening of the mucous membrane around the follicles, or in that part of

autopsies covers them. Louis found the patches of Peyer natural in twenty

demic of made by himself, of yellow-fever cases at Gibraltar, during the epi"Spleen. 1828.

the Spleen.- In one case the spleen was enlarged, soft, and breaking down under not alers; in another enlarged, gorged with blood, but firm. This viscus was

Was not from the normal condition in the other cases examined. The pancreas

larger not in any case otherwise than natural. The kidneys were mottled and

in which usual on one occasion. The bladder was in general collapsed. A case

"Thich bloody urine was voided was not inspected.

often morbid appearances observed in the intestines are very like those so

place to found in fatal cases of the typhoid fever of this country. This is not the

ing the recapitulate the evidence opposed to the doctrines of Broussais, regard-

rations nature of fever; but every day's experience tends to prove that the ulce-

and not the other lesions of the bowels are a specific effect of the fever poison, Me cause of the fever itself." 147.

Morbid changes of this kind were found in the intestines in all cases-

the feve of these changes were constant-and therefore not essential to Ther. In two cases the blood was found in a fluid state after death. memb main sequence of the African fever was an irratibility of the mucous
peared, of the bowels, continuing for a long time after the fever disapThis inted, no doubt, dependent on lesions contracted during the fever. often, intestinal irritability occasionally rises into enteritis, and is then, too ten, fatal.

Hepatic disease not unfrequently followed the gastro-enteric affection, by sympathy, contiguity or extension.

\section{Causes.}

The author has not been able to make any additions to what has long and known, or rather conjectured, respecting the etiology of remittent ve kntermittent fevers. That a certain something - the nature of which know not-is emitted from marshy localities-is acknowledged by all, 
as causing miasmal fevers, \&c-and that is the sum total of our know ledge !! The banks of the Niger offered no exception.

In respect to the latent period of the poison, our author remarks as follows :-

"When it is considered, as has been already noticed, that the vessels wert constantly exposed to endemic influence, while they remained in the Niger, it impossible to say at what time the miasmatous poison was first inhaled: but hardly think that it was imbibed by any individual before we left the mouth 0 the river : if this were so, then fever may be said to have ensued on the sixteent day* from the period of its earliest imbibition. Quarter-masters, seamen, and marines, whose duties were chiefly on deck, stokers in the engine-room, $0_{0} \mathrm{ks}$ and in short, men of various occupations and constitutionally dissimilar, wer simultaneously affected with fever.

"Upon the whole, I am inclined to think that in those cases which appeared al Iddah, the germs of the disease were contracted in the Delta. The stagnan state of the atmosphere, (relieved by occasional tornadoes,) and the causes malaric exhalation being still abundant, and accumulated in the lower part of the atmosphere, from the want of a wholesome agitation, were favorable in its de velopment at Iddah. Up to this point, the south-west breeze had always bet felt during part of the twenty-four hours. The miasma in this state of conded sation, so to speak, acted energetically upon men whose vital powers were alreads enfeebled, and who may have been for some time insensiby under its insidion influence.

"Moral causes came also into operation after leaving Iddah : many of those who were well were dispirited, and not a few, when taken ill, became speedly despondent.

"When out of the whole expedition there were only fifteen whites that werl not attacked with fever in the Niger, it is scarcely possible to offer any opinio as to how far the susceptibility to this treacherous disease was influenced by tell perament or idiosyncracy. Of the blacks, consisting of natives of various part of Africa, including Kroomen, Americans, West Indians of African origin an the East Indians, to the number of 158, eleven only were affected by the fever in river : they (the eleven) had all been in England, and for some years absent fro their respective countries. The disease in them assumed a comparatively min form, and in no case did it prove fatal; showing that the immunity from demic disease in warm countries, which is enjoyed by the dark races, is to a cel tain extent destroyed by a temporary residence in another climate.

"The question as to whether contagion contributed to the spread of the disease on board of the ships may, in my opinion, be briefly disposed of. All wert exposed to the same influences; and nearly all were attacked with fever. Tw only of the four medical officers who died had been in attendance on fer patients. Dr. Pritchett, Mr. Thomson, Mr. Stirling and Dr. Stanger were amono the few who escaped being seized with fever, although they were in constan intercourse with the sick; and I was the last person in the Albert laid down wh fever. The nurses on board the Albert were among the latest taken ill, an one escaped altogether. No fact came under my observation affording ther. slightest evidence that the disease was communicable from one person to anoth

"Does one attack of river fever afford any protection against a second?

"My own experience, added to information obtained from many of my brothe officers, and from Mr. King, the surgeon of the Ethiope, who has been more

* “ The Quorra, M‘Gregor Laird's vessel, entered the river on the 19th of * "The Quorra, M`Gregor Laird's vessel, entered the river on the 19 ' $0^{\circ}$
October, and fever broke out twenty-one days afterwards, on the 11 th of
vember." 
the Niger than

one attack than any other medical man, is wholly unfavorable to the opinion that

those who of river fever affords any immunity from a second. On the contrary,

disposed to it, once suffered from this treacherous disease seem particularly preAs a to it, if they again venture within malarious influence." 181 .

the a prophylactic, Dr. M'W. thinks himself authorised to recommend wine.

- TREATMENT OF THE FEVER.

is to is a very unsatisfactory subject. The very best mode of treatment out of the out the range of the cause as soon as possible-that is to get Egrum facit." into the open sea!- "Pessimum Agro cœlum est, quod General bleeding was not found to be successful in this fever. On the
contrary, it was injurious. Local bleedings, as cupping the temples, were
sometimes benos. metimes beneficial.

Blisters were often of great use.

Mood." tended In many cases "the full action of mercury would have been atwith with danger." "Calomel combined with opium, and afterwards remedy." Purgatives. - The bowels were generally constipated, and required active "Carges, especially in the early stage.

free "Calomel, jalap, and the bitartrate of potash were given at first, so as to cause

bowels hadions, which were in general dark or of a bilious character. After the

better had been well emptied, castor oil and the milder aperients answered given with strong purges; which then indeed do much harm. Enemata were

dered with benefit, when epigastric tenderness or irritability of the stomach, renthe administration of purgatives by the mouth inadmissible." 197.

Diaphoretics-_-The best of these was the true James's powder, which quinine the action of the skin without producing nausea. Sometimes was combined with it, and with good effect.

Quinine.-"In general when the tongue began to clean, and the other sympnine indicated that the functions were returning to their normal condition, quialone thas given in large doses with great benefit. But it was not to this period cases in the use of this valuable remedy was restricted, for there were many necessary which, from the tendency to sinking from the very beginning, it was the Nigery to commence with quinine, wine, and light soups. In a disease like exhibitier fever, so little amenable to treatment, no rule can be laid down for the quinine of a particular remedy; but no medicine was found so efficacious as protracted diminishing the severity of the paroxysms. In some of the more that whated cases, the red tinge over the sharp features would occasionally indicate establish atever power of reaction rernained in the wasted system, was exerted to by the libeeble exacerbation, the exhaustion following which was often lessened liberal use of quinine. 
"Brandy, wine, camphor, opium, and ammonia were freely given when the pulse began to flag, and when the symptoms generally denoted depression ${ }^{0}$ vital energy ; and often with almost miraculous effect, as in Case xiII.

" Sponging the body with tepid water and vinegar, in general afforded relief but I never could carry the cold affusion further than the application of larg wet clothes to the head. The warm bath was not much used, and in those cases in which it was tried the benefit obtained was only temporary, the relaxation and exhaustion produced by it, contra-indicated its general use in a disease which marked by debility and tendency to sinking; tenderness at the epigastrium $12^{2}$, however, often relieved by applying to it a japanned case filled with hot waters and concave so as to fit closely to the abdomen. A large oblong case of siml the construction was advantageously applied to the feet during the low stage of the disease ; and at earlier periods, when the nervous depression retarded the develop? ment of the stage of re-action, in which case the extremities often continul cold after the chest and abdomen had become quite hot." 199.

The foregoing general remarks are illustrated by numerous cases with their details; but to these we need not refer. A good many pages at dedicated to the economy of the vessels, as ventilation, provisions, med cines, \&c. \&c. as well as to meteorology, \&c. which will prove vet? interesting to naval surgeons, and naval officers whose destiny may leal them to the pestiferous shores of Africa-and especially into that fat river, the Niger.

The volume is written with great modesty, and indicates, in every pagh good sense, discernment, and both practical and scientific knowledge.

\section{Catalogue of the Preparations illustrative of Normath Abnormal, and Morbid Structure, Human and Comps rative, constituting the Anatomical Museum of Geor ${ }_{0}^{\circ}$ Langstaff, \&c. \&c. London, Churchill. 1842.}

IT was, we believe, old Dr. Gregory of Edinburgh, who used so earnestl? to impress on the minds of his pupils the vast importance of assiduous? perusing Morgagni's celebrated work De Sedibus et Causis Morborum the terms, Nocturnd versate manu, versate diurna. The habit of connectin? the morbid appearances found after death with the symptoms obserse during life, and of placing them, as it were, in juxta-position, being the very best, nay in fact the only means of preparing and qualifying medical practitioner for attaining and forming a correct diagnosis the bed-side of his patient. To point out the value and importance studying morbid structure and of tracing it through all its stages an gradations from the first blush of capillary redness to the final disorgall sation of parts, would at the present day be a work of supererogatio That the thing is fully recognized, the numerous Anatomical Museum ${ }^{5}$. Morbid Structure throughout the metropolis evince. The opportuniti of studying this important branch of pathology in London, containing it does, the Hunterian Museum, that stupendous monument of hum industry, together with the numerous other Museums attached to th 